\title{
O Conhecimento em Análise na Formação de Professores de Ciências Biológicas
}

\section{The Knowledge Under Analysis In The Training of Biological Sciences Teachers}

\author{
Alessandra Batista de Godoi Branco ${ }^{1}$; Susane Closs da Silva ${ }^{2}$; Emerson Pereira \\ Branco $^{3}$; Lucila Akiko Nagashima ${ }^{4}$
}

1 Doutoranda, Universidade Estadual de Maringá, Maringá, Paraná, Brasil - alessandra_g12@ hotmail.com, /ORCID 00000003-3488-592X

2 Mestra, Universidade Estadual do Paraná, Paranavaí, Paraná, Brasil - susane_bibi@ hotmail.com, /ORCID 0000-00032601-4008

3 Mestre, Universidade Estadual do Paraná, Paranavaí, Paraná, Brasil - ems_branco@ hotmail.com, /ORCID 0000-00033597-0392

4 Doutora, Universidade Estadual do Paraná, Paranavaí, Paraná, Brasil - lucilanagashima@uol.com.br, /ORCID 0000-0001$8197-9668$

\section{Recebido em Outubro/2018. Publicado em Agosto/2020}

\section{Palavras-chave:}

Epistemologia. Ensino e aprendizagem. Escola.

Desenhos.

\section{Keywords:}

Epistemology. Teaching and learning. School. Drawings.
RESUMO: O artigo é resultado de pesquisa qualitativa com revisão de literatura e documental. Nesse estudo, objetivou-se analisar a percepção de um grupo de licenciandos em Ciências Biológicas sobre o conhecimento no processo de ensino e de aprendizagem no contexto escolar. A partir disso, buscou-se relacionar a modelos pedagógicos e epistemológicos, de acordo com referencial teórico. Para tanto, os objetos de análise foram atividades realizadas pelos participantes: (1) a resposta à pergunta sobre concepção de conhecimento e (2) desenhos sobre como se dá o conhecimento no processo de ensino e de aprendizagem na escola. Nos encontros foram produzidos escritos e desenhos, os quais foram lidos, observados, estudados e categorizados pelo método de análise de conteúdo. Como resultado, os participantes da pesquisa apresentaram concepções variadas de conhecimento sobressaindo características da tendência empirista, valorizando a exposição, a ideia de transmissão, a reprodução, entre outros. Os desenhos representaram concepções ligadas principalmente ao empirismo e ao construtivismo. Em relação aos indivíduos retratados, foi mais recorrente a figura da professora à frente da turma, distante dos alunos e expondo o conteúdo. Os estudantes foram desenhados por todos os acadêmicos, a maioria sem distinção de gênero, sentados e passivos ou em pé, aparentemente alheios à aula. Foram representadas interações interpessoais e muitos dos estudantes voltados fisicamente em direção ao professor. Sobre o espaço, sobressaiu a sala de aula, com quadro, carteiras enfileiradas e giz. Assim, o modelo pedagógico sugere que características do empirismo foram mais recorrentes nas atividades elaboradas pelo grupo participante.

ABSTRACT: The article is the result of qualitative research with literature and documental review. It analyzed the perception of students in Biological Sciences course about knowledge in the teaching and learning process in the school context. It was tried to relate to pedagogical and epistemological models, according to theoretical reference. For this purpose, the objects of analysis were activities done by the participants: (1) the answer to the question about conception of knowledge and (2) drawings about how knowledge is given in the teaching and learning process at school. During the meetings, writings and drawings were produced, which were read, observed, studied and categorized by the content analysis method. As a result, the participants presented varied conceptions of knowledge, highlighting the characteristics of the empirical trend, valuing exposure, the idea of transmission, 
reproduction, among others. The drawings represented conceptions linked mainly to empiricism and constructivism. In relation to the subjects represented, the figure of the teacher at the head of the class, distant from the students and exposing the content, was more recurrent. The students were drawn by all the academics, most without distinction of gender, seated and passive or standing, apparently unconnected to the class. Interactions were represented among the subjects and many of the students physically oriented towards the teacher. In terms of the space, the classroom stood out, with a board, lined desks and chalk. Thus, the pedagogical model indicates what characteristics of empiricism were most recurrent in the activities developed by the participating group.

\section{INTRODUÇÃO}

Entender o conhecimento, a forma como é vivenciado e como esta dimensão é relevante e influencia na vida, no funcionamento e na manutenção da sociedade, nas formas de aprender, traz novas demandas, entre outros aspectos que envolvem diretamente a educação, é tema de estudo para muitos autores, entre os quais é possível citar Coutinho e Lisbôa (2011), Gimeno Sacristán (2013) e Frigotto (2008).

Tal alusão mostra o quanto o conhecimento e a informação estão imbricados na sociedade e na vida dos indivíduos. Nesse contexto, a escola adquire local de destaque enquanto instituição formadora, cujo principal objetivo é (ou deveria ser) o conhecimento. Mas, a que se refere esse conhecimento? Há uma percepção "única" e "verdadeira"?

Enquanto ramo da filosofia, a epistemologia problematiza, estuda e elucida a produção do conhecimento em diferentes abordagens (como lógica, ideológica, política, sociológica, entre outras). Ao mesmo tempo em que propõe intensas reflexões, é indispensável em qualquer nível de formação, pois relaciona enaltecer a própria razão da prática educativa e, assim, vislumbrar seu valor imensurável para cada indivíduo, para a sociedade e para a humanidade (OLIVEIRA, 2016). Desse modo, é possível concordar que refletir sobre a origem e importância do conhecimento são aspectos essenciais no processo formativo, especialmente de professores.

Para Libâneo (2016), é preciso questionar “para que servem as escolas”, atentando-se das influências externas sobre a concepção de escola e de conhecimento escolar. Essa reflexão também é feita por Masschelein e Simons (2014) e Saviani (2011), dentre outros autores. Trata-se de um aspecto pertinente, pois a seleção de conteúdos e conhecimentos, assim como a forma como esses são apresentados aos educandos, refletem o objetivo da instituição, o seu ideal formativo, o projeto político pedagógico assumido, a formação e a prática docente, entre outros aspectos.

Em relação à formação de professores, Becker (2013, p. 334) afirma que a concepção epistemológica é "efeito e não causa", alegando que pode determinar sua prática pedagógica. Esse entendimento corrobora com Gimeno Sacristán (2000), ao dizer que a valorização do conhecimento influencia na prática e escolhas sobre o processo de ensino e aprendizagem. 
Nesse sentido, o entendimento que se tem sobre o conhecimento, sua epistemologia, é um dos fatores preponderantes sobre abordagens, objetivos e ações - inclusive no que se avalia sobre o "conhecimento escolar" (conteúdos, currículo) e de qual tipo, e os métodos de ensino e de avaliação, por exemplo.

Segundo Aranha (1996), as concepções sobre o conhecimento usualmente derivam de duas linhas: o racionalismo ${ }^{1}$ (subjetivismo, idealismo, apriorismo, inatismo), com referência à Descartes e o empirismo ${ }^{2}$, sob influência de Locke, Comte e Durkheim. A autora afirma que tais tendências não são suficientes para explicar toda a complexidade cognitiva e, em busca de compreensões mais elaboradas, surgem outras como a fenomenologia ${ }^{3}$ que não apresenta uma posição unilateral entre sujeito e objeto, mas considera uma afinidade intrínseca entre estes e são chamadas de teorias progressistas e construtivistas.

Nessa vertente, Becker (2012) relaciona modelos pedagógicos (pedagogia diretiva, não diretiva e construtivista) e epistemológicos (empirista, apriorista e construtivista) que retratam diferentes percepções acerca do conhecimento. $\mathrm{O}$ autor considera que os modelos fundamentados nas epistemologias empirista e apriorista são acríticos e de senso comum. A superação, segundo defende, é uma epistemologia crítica e, para isso, salienta como um estudo imprescindível na formação de professores.

Para Becker (2012), a epistemologia do professor interfere em sua prática, na organização da sala de aula, nas relações entre os estudantes e professores, na metodologia, entre outros aspectos. Tal justificativa dialoga com Aranha (1996), ao dizer que os critérios de seleção de conteúdos, métodos e procedimentos, a maneira de tratar com as dificuldades de seus alunos, entre tantas práticas e tomadas de decisão, tudo é questão epistemológica que se manifesta em sua práxis.

Nesta ideia e, partindo destas primeiras reflexões, este trabalho propõe analisar a percepção que os acadêmicos de licenciatura em Ciências Biológicas têm sobre o conhecimento no processo de ensino e de aprendizagem, no contexto escolar. A partir disso, buscamos relacionar a determinados modelos pedagógicos e epistemológicos, de acordo com referencial teórico. Para tanto, os objetos de análise foram atividades feitas pelos participantes da pesquisa.

O grupo participante foi composto por 20 acadêmicos do $3^{\circ}$ ano de um curso de licenciatura em Ciências Biológicas, de Universidade pública situada na região Noroeste do Paraná. As atividades analisadas foram: as respostas de uma questão discursiva e desenhos.

A pesquisa foi organizada em seções, que tratam dos seguintes temas: (1) revisão de literatura sobre epistemologia, problematização e abordagens acerca do conhecimento; (2)

\footnotetext{
${ }^{1}$ Na relação sujeito-objetivo, esta concepção privilegia o sujeito.

${ }^{2}$ Ênfase na experiência, no objeto. O sujeito é considerado uma tábula rasa.

${ }^{3}$ Entre sujeito e objeto, considera o fenômeno, a dialética, o sentido, os significados.
} 
recursos metodológicos utilizados para coleta e análise dos dados e (3) resultados com base na interpretação em diferentes categorias.

\section{A [DES]VALORIZAÇÃO DO CONHECIMENTO NA SOCIEDADE E NA ESCOLA}

O que é o conhecimento? Qual é o seu lugar na sociedade e na escola? Como é construído, compartilhado, refutado? No contexto da educação formal, como se dá o processo de ensino e aprendizagem dos "conhecimentos escolares" que compõe o currículo? Em busca dessas reflexões, atemo-nos para um contexto mais amplo, que é a sociedade.

Coutinho e Lisbôa (2011) apresentam os conceitos de informação, conhecimento e aprendizagem no contexto da globalização, da exacerbação de recursos tecnológicos, avanços científicos, na interação que "derrubou” fronteiras entre países, culturas e pessoas, assim como expandiu e acelerou a difusão e o acesso ao conhecimento. Salientam o quão vastas são as formas disponíveis para aprender e, nesse contexto, a escola é desafiada diante das constantes mudanças na sociedade, na qual entendem que o conhecimento pode ser aprendido por significação, interiorização, reflexão, estabelecendo conexões e por aprendizagem significativa. Nesse sentido, é possível considerar aspectos em que essas transformações inferem nas formas de acesso do conhecimento e da informação, relacionando-as a educação.

De acordo com essa proposição, conceitos de "sociedade da informação ou do conhecimento e educação aparecem inter-relacionados em seus significados, ainda que obedeçam às lógicas que podem ser, em parte, coerentes e, em parte, contraditórias" (GIMENO SACRISTÁN, 2013, p. 158). Entre outros aspectos, o autor alega que na "sociedade do conhecimento" há difusão de informações, formas de comunicar e aplicar a informação, tornando indispensável manter uma conexão da educação formal com esta sociedade. Diante dessas considerações, no contexto da globalização, é possível afirmar que há uma sociedade do conhecimento? O acesso está posto de forma homogênea para todos? Essas transformações são [apenas] positivas? Infelizmente, não foi possível declarar "sim" para esses questionamentos.

Frigotto (2008, p. 17) considera que a "ideologia da globalização e da sociedade do conhecimento e do determinismo tecnológico" pode conotar (erroneamente) apenas aspectos positivos, mas lembra das desigualdades. Isto se nota por meio de um pensamento críticosocial, pela notória falta de prioridade que se dá a educação, pela exploração do trabalhador, pela desigualdade de uma universalização da educação básica, pela diferença e dualidade no "acesso efetivo e democrático do conhecimento" (FRIGOTTO, 2018, p. 23).

Conforme ressaltado, não é possível afirmar que o acesso ao conhecimento é igual, inclusivo, democrático, tampouco eficaz. São diferentes formas e níveis de acesso e, entre essas, está a escola. 
Entre algumas das “acusações" feitas à escola, Masschelein e Simons (2014, p. 9) citam a de reproduzir a desigualdade, alegando não haver igualdade no acesso e no tratamento. Isso ocorre porque no contexto do capital, "o conhecimento é um bem econômico e há uma hierarquia de formas de conhecimento que a escola reproduz". Essa é a escola dual, em que ainda é preciso superar as diferenças no acesso a "conhecimentos culturais e científicos”, revelando “desigualdades educacionais" (LIBÂNEO, 2016, p. 38).

Versar sobre tais disparidades, não significa desconsiderar a diversidade das escolas e das pessoas que dela participam e nela se relacionam, aprendendo e ensinando, mas se relaciona com a desigualdade planejada e assistida: para uns isso e para outros aquilo; aqueles saberão, mas outros, não. Ironicamente, a sociedade do conhecimento obstrui e segrega a razão e o entendimento a muitos. Nesse contexto, qual deve(ria) ser a função da escola?

Para Saviani (2011, p. 14), sua função principal é socializar o saber sistematizado, elaborado e propiciar meios para acessá-lo. Para explicar, apresenta três entendimentos/palavras:

Em grego, temos três palavras referidas ao fenômeno do conhecimento: doxa ( $\delta$ ó $\xi \alpha)$,

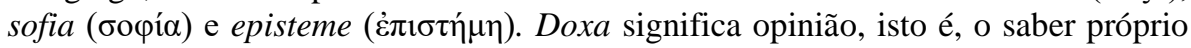
do senso comum, o conhecimento espontâneo ligado diretamente à experiência cotidiana, um claro-escuro, misto de verdade e de erro. Sofia é a sabedoria fundada numa longa experiência de vida. É nesse sentido que se diz que os velhos são sábios e que os jovens devem ouvir seus conselhos. Finalmente, episteme significa ciência, isto é, o conhecimento metódico e sistematizado.

São tipos distintos de conhecimento, cada um com sua especificidade e reconhecimento. Entre esses, Saviani (2011) defende o saber sistematizado e a cultura erudita e letrada na escola, situando sua função, seu compromisso e o lugar que deve ocupar.

Luckesi (2011) entende que o conhecimento se relaciona à compreensão da realidade, do contexto e de si mesmo, e a escola deve oferecê-lo aos seus educandos. Masschelein e Simons (2014) afirmam que o conhecimento é um bem econômico e cultural e que o "conhecimento escolar" - o que ensina, a matéria de estudo -, reflete as características da função pública da escola.

Tais considerações remetem a uma descrição do que pode ser a essência, o sentido da instituição escolar enquanto ambiente próprio para aprender, ensinar, formar e estudar. Assim, é possível afirmar que se trata de um assunto não apenas necessário, mas indispensável para a formação e a prática docente.

De acordo com Libâneo (2013, p. 20-21), a escola é o lugar "específico de atuação do profissional e política do professor", em que se deve assegurar aos estudantes o "domínio de conhecimentos e habilidades, o desenvolvimento de suas capacidades intelectuais, de 
pensamento independente, crítico e criativo". Como já enfoca, a escola e o fazer docente têm objetivos indissociados e, entre eles, está o conhecimento.

Assim, a atuação e a perspectiva epistemológica da professora e do professor não são neutras. Sobre esse aspecto, Gimeno Sacristán (2000, p. 187-188. Grifos do autor) apresenta o seguinte entendimento:

\begin{abstract}
A valorização do conhecimento é uma dimensão importante na configuração de um estilo pedagógico, uma orientação curricular ou uma determinada orientação filosófica sobre a educação. [...] Como se concebe o conhecimento, como se ordena, que papel se concebe para sua relação com a vida cotidiana, qual é sua origem, como se valida, como evolui, a ponderação de seus componentes, como se comprova sua posse, etc. são aspectos cruciais sobre os quais se interrogar num modelo de ensino para analisar sua especificidade. O professor não tem muitas oportunidades de tratar essas dimensões epistemológicas dos métodos didáticos e nos currículos, nem são, com frequência, sequer discutidas no transcurso de sua formação. Suas posições a respeito, ainda que sejam implícitas, costumam ser adquiridas e assimiladas por osmose, e não é fácil que possa expressá-las de forma vertebrada e coerente.
\end{abstract}

No contexto da formação de professores, o autor alerta que os dilemas epistemológicos ainda são ocultos, poucos considerados, o que pode reforçar concepções prévias dominantes acerca do conhecimento, como se não precisasse ser discutido. Entretanto, pondera que a concepção influencia o docente ao: selecionar conteúdos, na constituição do currículo, nos métodos, e em muitas decisões e ações da sua prática.

A partir dessas considerações, assumimos o entendimento de que há diferenciação do conhecimento e de que o processo de ensino e de aprendizagem, as tomadas de decisão e práticas assumidas pela escola e por seus professores, são influenciadas pela concepção desses sujeitos sobre o conhecimento e perpassam dilemas epistemológicos.

\title{
RECURSOS METODOLÓGICOS
}

A trajetória para a construção do estudo foi resultado de encontros realizados com os acadêmicos do $3^{\circ}$ ano do curso de licenciatura em Ciências Biológicas de uma Universidade pública do Noroeste do Paraná, em estudos do componente curricular Estágio Supervisionado. Para a pesquisa qualitativa, foi utilizado o método da pesquisa-ação, para a qual Chizzotti (2006) apresenta as seguintes fases: definir o problema, formular o problema, implantar, executar, avaliar e prosseguir a ação.

Essa pesquisa foi realizada no primeiro semestre de 2017, em seis encontros. Havia 20 acadêmicos matriculados na turma. Os dados coletados foram textos e desenhos produzidos pelo grupo em dois encontros.

Para o planejamento dos encontros, a primeira ação foi investigar a concepção dos acadêmicos sobre o tema. Para tanto, o instrumento de coleta de dados foi a questão: "Qual é 
a sua concepção sobre: conhecimento?’. Essa pergunta foi respondida por 17 estudantes. As produções foram transcritas em resumo e serviram a uma visão diagnóstica e introdutória para a pesquisa.

Em outro encontro, o tema de estudo foi conhecimento nas dimensões artística, filosófica e científica do conhecimento; o conhecimento sistematizado (científico) e do cotidiano popular (senso comum); o conhecimento e as disciplinas escolares. Nesse momento, foi apresentada a síntese das respostas, que foram analisadas sob referencial teórico.

No mesmo encontro, foi solicitada uma atividade vinculada à dimensão artística de conhecimento: a produção de desenhos para expressar como percebiam que ocorre a transmissão e/ou assimilação e/ou construção de conhecimento no processo de ensino e aprendizagem. A escolha por essa forma de expressão considerou a criação como um atributo da dimensão artística, que se manifesta num "fazer algo inédito, novo e singular, que expressa o sujeito criador e simultaneamente, transcende-o, pois, o objeto concreto é uma nova realidade social" (PEIXOTO, 2003, p. 39).

Foram elaborados 15 desenhos. O material foi analisado por meio de categorização, utilizando o método de análise de conteúdo (BARDIN, 2011) como meio para decodificar os elementos apresentados. Para tanto, elaboramos categorias que serviram para apresentar as multiplicidades de concepções por via descritiva.

Considerando tais análises, foram selecionados alguns desenhos para mostrar possíveis reflexões. Para tanto, optou-se por organizar alguns exemplos e apresentar considerações, relatos e referências que pudessem contribuir para a observação e leitura das produções. Para respeitar a identidade dos participantes, foram apresentados por Acadêmico seguido do número. Por fim, todos os desenhos foram analisados a partir dos seguintes aspectos: (1) sujeitos - professores e estudantes, (2) interações e (3) espaços e recursos.

\section{RESULTADOS}

Ao serem questionados sobre o que é conhecimento, em uma investigação diagnóstica, os acadêmicos apresentaram preceitos de que o conhecimento é: resultado de experiências, aprendizagens, teorias, pesquisas e estudos; uma ideia, um conceito; se opõe a decorar; sinônimo de saber, aprender e reproduzir; comprovado por experiência - aplicado, validado; necessário à sobrevivência e, por isto, deve ser transmitido entre as gerações e a todos; mutável, não está pronto e acabado; historicamente acumulado.

Aranha (1996, p. 133) afirma que o pressuposto epistemológico está ligado à sua práxis pedagógica. Sobre isso, explica que, ao assumir uma tendência empirista, por exemplo, a prática docente assume características de um ensino tradicional, tais como: "a valorização da aula expositiva enfatiza o ensino como transmissão de conhecimento, o conhecimento 
como produto acabado, a memória como arquivo, a aprendizagem como soma, acumulação quantitativa", que se aproximam ao senso comum, com ênfase ao treinamento e a programas preestabelecidos.

Nessa perspectiva, ao entender o conhecimento como resultado da experiência e por essa comprovado, as experiências tendem a ser valorizadas e até exigidas no processo de ensino e aprendizagem. Em outro entendimento, uma apresentação oral sobre determinado conteúdo, pode ser percebida como suficiente para que os ouvintes assimilem o conteúdo que foi "transmitido", aprendam o que foi exposto. Esses exemplos mostram a concretização do método a partir de determinada concepção, o que infere em níveis de exigência e de expectativas sobre como se aprende e se ensina.

Na sequência, analisamos desenhos produzidos pelos acadêmicos como expressão da forma como percebiam que ocorre a transmissão, assimilação ou construção do conhecimento no processo de ensino e de aprendizagem na escola. Assim, puderam representar esse significado em imagem.

Inicia-se com as observações sobre a sala de aula, cuja categoria foi denominada de transmissão de conhecimento na sala de aula (Figura 1):

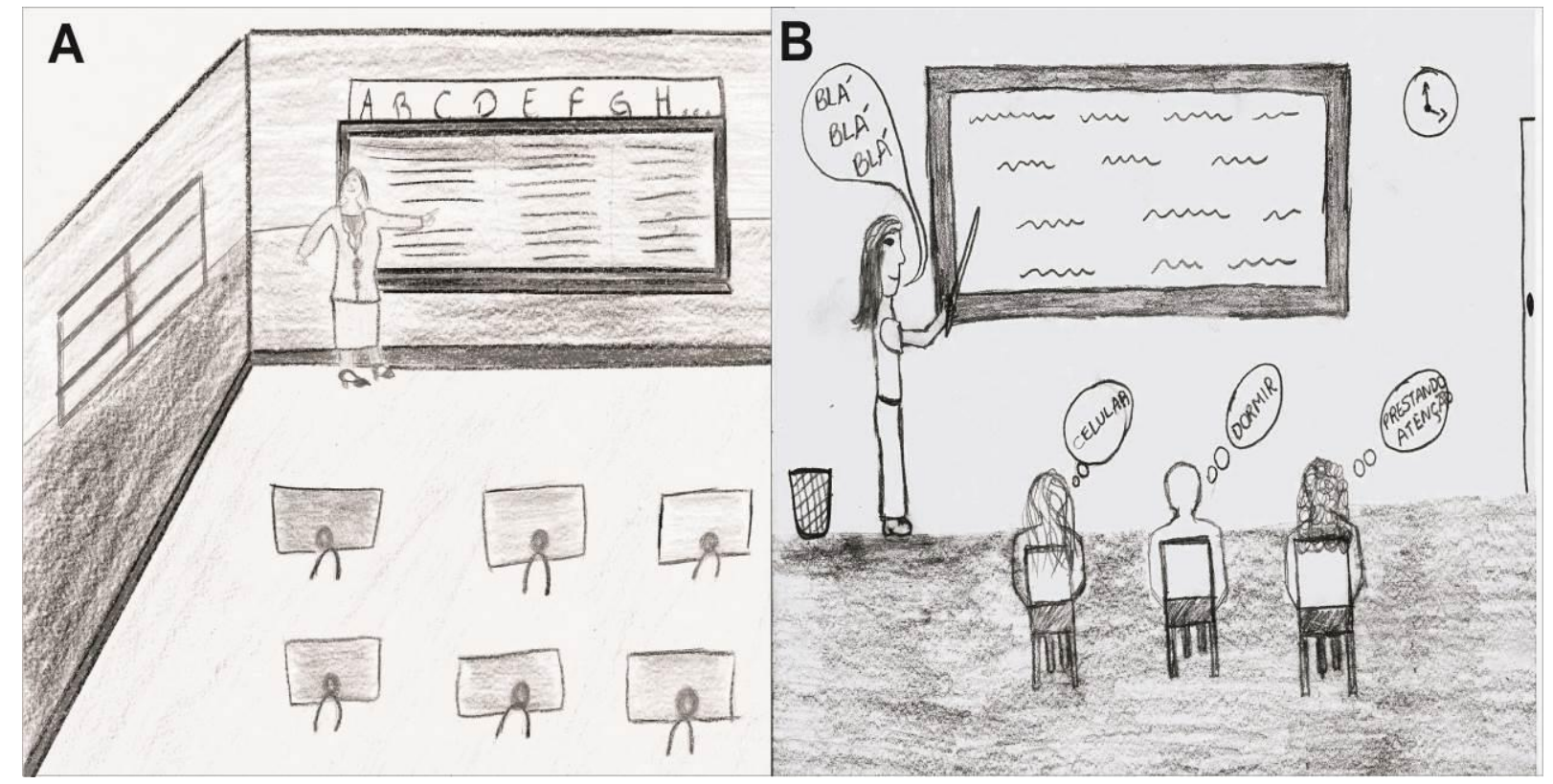

Figura 1 - Desenhos de acadêmicos de licenciatura sobre a sala de aula e a transmissão de conhecimento.

Fonte: Os autores. Autor do Desenho A: acadêmico 11 e do B: acadêmico 5.

Nos Desenhos A e B foi mostrado o local da sala de aula, numa organização "habitual". A exposição oral, o quadro com anotações em giz sendo indicadas e a disposição dos discentes (organizados em fileiras) são algumas características do ensino tradicional, que apareceram com recorrência nos desenhos do grupo participante e, possivelmente, em suas experiências. Foi possível notar, na Figura 1, a comunicação oral e escrita aparentemente 
vinculada ao ensinar e ao aprender. Por tais características, selecionamentos essas imagens como exemplos da ideia de transmissão.

Becker (2013, p. 144) afirma que "a aprendizagem, entendida como transmissão de conhecimento, constitui a marca registrada do empirismo" e que, nessa visão, entende-se que o conhecimento "se dá por força dos sentidos" e que é "algo que vem do mundo do objeto (meio físico ou social); portanto, o mundo do objeto é determinante do sujeito, e não o contrário" (BECKER, 2013, p. 12). Há, portanto, valorização da hierarquia e da transmissão em detrimento do diálogo.

Segundo Masschelein e Simons (2014), a forma como a sala de aula é construída, ferramentas e métodos são escolhidos e a própria posição dos professores são reflexos de determinada ordem social. Uma crítica comum, é que "para muitos a lousa e a carteira são a quinta-essência dos artefatos da educação clássica: armas para disciplinar os jovens, arquitetura a serviço da pura transferência de conhecimento, símbolos do professor autoritário" (MASSCHELEIN; SIMONS, 2014, p. 24). Como já enfocam, o estudo e a prática, o arranjo físico e as relações estabelecidas nesse espaço podem refletir ideais de ordem social - para sua manutenção ou superação.

O que difere no Desenho B é a ilustração de fala ${ }^{4}$ da professora e de pensamento ${ }^{5}$ dos estudantes que, embora apresentem a mesma postura corporal, a posição e o [des]interesse em relação ao conteúdo aparentavam ser distintos, o que infere que nem todos aprendam, embora recebam a mesma exposição. A imagem mostra diferentes interesses e, por isto, possivelmente nem todos se apropriam dos conteúdos apresentados ou, em outra vertente, a ausência referida por Luckesi (2011, p. 116), ao afirmar que "psicologicamente, quando o educando não compreende o que está sendo exposto, ausenta-se".

$\mathrm{Na}$ sequência, para compor a Figura 2 selecionamos percepções que se que relacionam ao conhecimento como construção, conexão e troca entre os sujeitos:

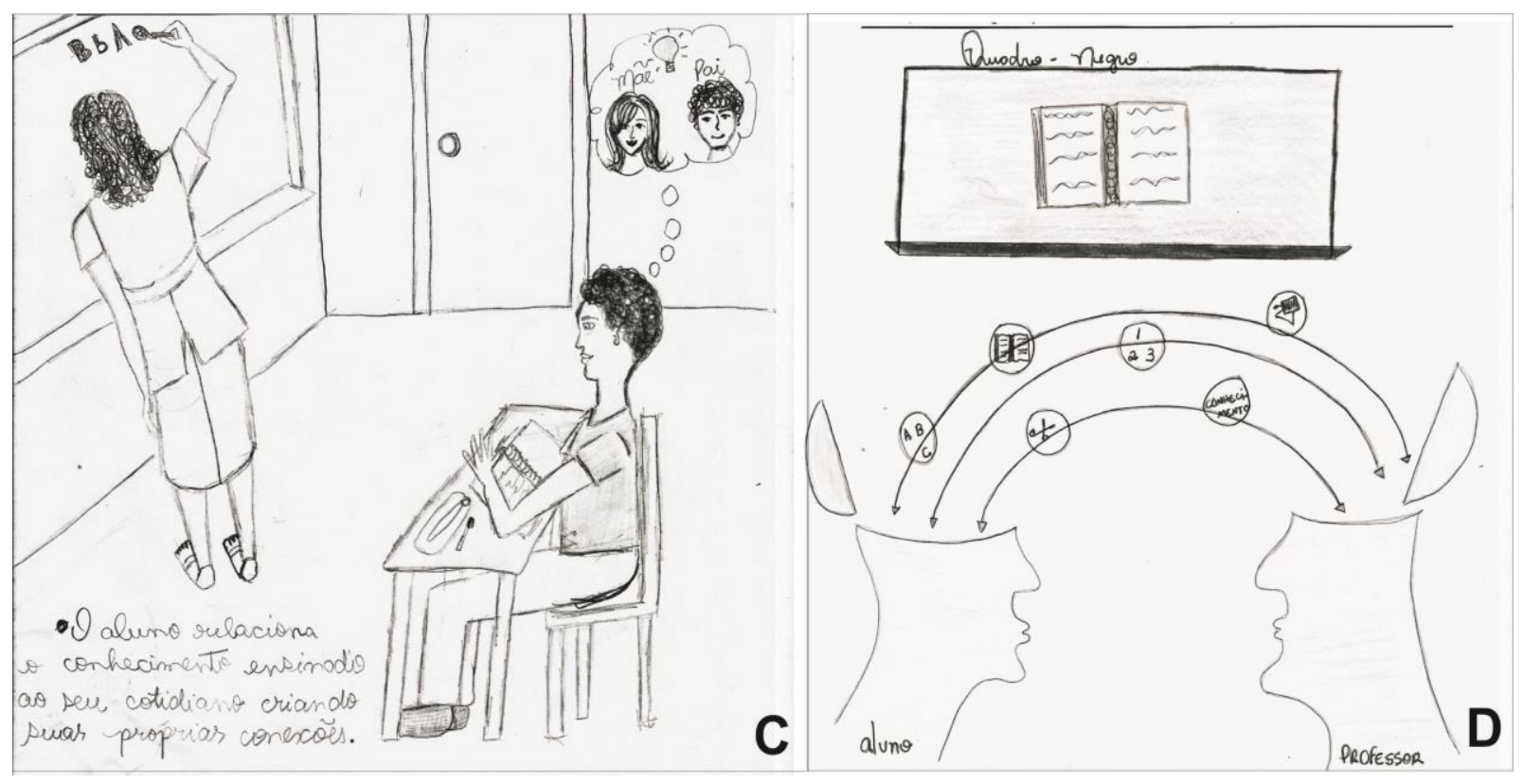


O conhecimento, enquanto construção e assimilação, pode ser percebido no Desenho C (Figura 2): a professora, de costas para o discente, escreve um conteúdo. O estudante aprende ao relacionar tais conhecimentos ao seu cotidiano, conforme escreveu. Foram evidenciados saberes e experiências prévios, que fazem parte da aprendizagem, da construção de novos conhecimentos e conexões.

Para Becker (2013, p. 21), na teoria da assimilação ou construtivista, “as verdadeiras formas ou estruturas de conhecimento são resultados de um processo de interação radical entre o mundo do sujeito e o mundo do objeto, (inter)ação ativada pela ação do sujeito". De acordo com Saviani (2013), o construtivismo, cuja fonte é a obra de Piaget, tem relação com a Escola Nova, em que a psicologia genética emerge como base psicopedagógica do processo de aprendizagem. Nessa teoria, o ponto de partida e a ideia principal é a ação. Assim, o sujeito

Figura 2 - Desenhos de acadêmicos de licenciatura sobre o conhecimento como construção, conexão e troca entre os sujeitos.

Fonte: Os autores. Autor do Desenho C: acadêmico 1 e do D: acadêmico 8.

epistêmico constrói seus esquemas de apreensão.

Também é possível considerar que o conhecimento seja troca entre os sujeitos e, neste processo, podem aprender na relação com o outro (Desenho D, Figura 2). Nesta imagem nota-se que a informação advém na relação professor-aluno, no diálogo e no respeito pelas experiências do outro, independente da função que ocupa no ambiente escolar. Por isso, pareceu haver uma interação dialógica.

Cunha (2012, p. 150-151), em sua pesquisa sobre a relação professor-aluno, apresenta que esta relação tem a ver com o conteúdo e "a forma como o professor se relaciona com sua própria área de conhecimento [...], sua percepção de ciência e de produção de conhecimento, que se entretém a metodologia e se utiliza formas dialógicas de interação”. Assim, indica-se aspectos que intervêm na relação professor-aluno.

Em outro significado, o conhecimento, por vezes, também é imposto aos sujeitos, exigidos pelo cumprimento de conteúdos previamente estabelecidos ou pela própria sociedade. É possível remeter a Educação Bancária (FREIRE, 1987), em que ocorre um depositar de informações, sem criticidade e participação. A Figura 3 pode representar essa percepção: 


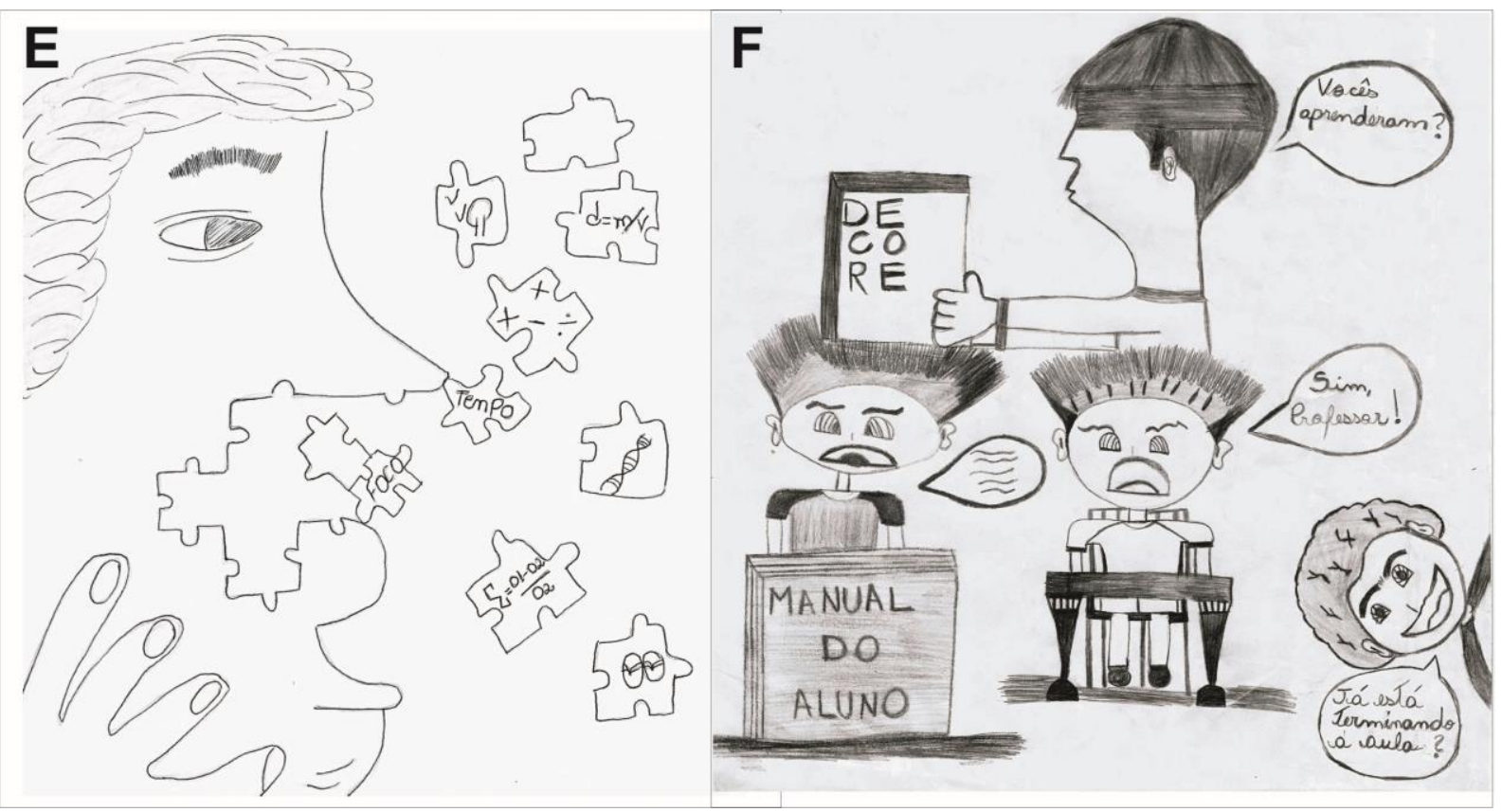

Figura 3 - Desenhos de acadêmicos de licenciatura sobre o conhecimento imposto, prescrito e depositado. Fonte: Os autores. Autor do Desenho E: acadêmico 3 e do Desenho F: acadêmico 9.

Em análise aos Desenhos E e F, é possível observar que mostram estudantes e professores alheios aos processos decisórios quanto aos conteúdos a serem ensinados e aprendidos, que ficam à mercê de questões externas. Essa situação pode ser exemplificada por: cumprir listas, memorizar/arquivar informações, aprender a aprender, e outras determinações.

O Desenho E sugere que o indivíduo, para se constituir, vai "encaixando" conteúdos moldados previamente, os quais devem ser internalizados em determinado tempo. Faz alusão aos estudantes, que geralmente precisam decidir muito cedo a profissão a seguir e, para se preparar para o vestibular, por exemplo. Nessa perspectiva, apresenta o sujeito como um "quebra-cabeças" que é considerado completo de acordo com determinadas aptidões, informações, habilidades e competências que lhe são exigidas. Visto de outro modo, essas exigências também poderiam fragmentá-lo, desconstruí-lo, em processo antagônico.

Tal ideia nos remete às exigências de "eficácia (atingir a meta), a eficiência (atingir o objetivo de forma rápida e com baixo custo) e o desempenho (alcançar cada vez mais com cada vez menos)" (MASSCHELEIN; SIMONS, 2014, p. 12) que podem caracterizar a escola como um negócio com exigências de produtividade - as quais são repassadas aos sujeitos que dela participam.

O Desenho F exibe o professor e seus alunos submissos a métodos de transmissão e assimilação de conteúdos postos em manuais ou livros didáticos. A imagem lembra o tecnicismo com sujeitos sem participação ativa, reflexão e motivação. Pode caracterizar um depósito de informações, como descreve Freire (1987) ao explicar a Educação Bancária. 
De acordo com Saviani (2013, p. 381), a concepção pedagógica tecnicista pressupõe "neutralidade científica" e se inspira "nos princípios de racionalidade, eficiência e produtividade". O autor descreve como uma política voltada para a uma educação interessada em formar recursos humanos, em aumentar a produtividade com redução de custos - um processo educativo "objetivo e operacional". Em termos epistemológicos, Becker (2013) considera que a compreensão de memória como arquivo e captação de informações "vindas de fora" caracterizam a concepção empirista de conhecimento.

Em outro aspecto, o conhecimento foi representado em atividades práticas e experimentais (Figura 4):

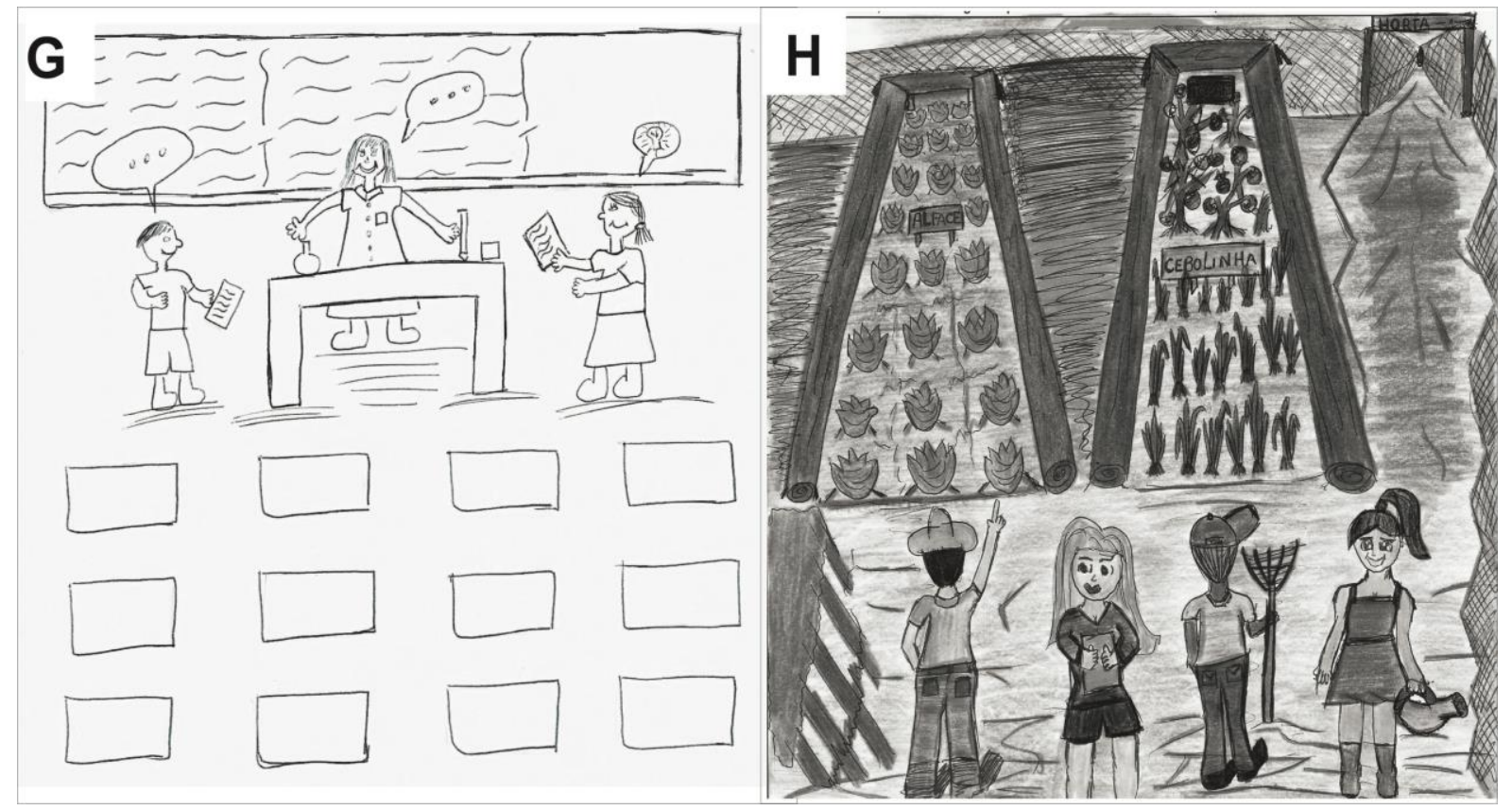

Figura 4 - Desenhos de acadêmicos de licenciatura sobre o conhecimento relacionado à teoria e à prática.

Fonte: Os autores. Autor do Desenho G: acadêmico 2 e do desenho H: acadêmico 14.

O Desenho G mostra uma professora em uma atividade experimental e é possível notar diálogo e interação. Nota-se a teoria e/ou atividades registradas no quadro e nas folhas dos estudantes. Há aspectos que indicam: pensamento, comunicação e ideias. O Desenho H mostra um projeto $^{6}$ da universidade, que é uma horta cultivada no campus. Conforme explicou, o acadêmico 14 considerava que o conhecimento se adquire na prática e, para isto, optou por desenhar sua vivência no projeto que, conforme demonstrou, proporcionava aos participantes uma aprendizagem significativa pela experiência, aliando teoria e prática.

Nesse sentido, é possível relacionar ao ponto de vista de que na ação, repercussão e interação do sujeito sobre o objeto é que se constrói o conhecimento (BECKER, 2013). Nos

\footnotetext{
${ }^{6}$ Trata-se de um projeto de extensão "UNIVERSIDADE SEM FRONTEIRAS", cujos coordenadores são dois professores do colegiado de Ciências Biológicas da Universidade da pesquisa. Em 2017, contava com cinco bolsistas, subsidiadas pelo Fundo Paraná. Tempo de existência: três anos e meio.
} 
dizeres de Saviani (2013, p. 435) "o entendimento de que a fonte do conhecimento não está na percepção, mas na ação, conduz à conclusão de que a inteligência não é um órgão que imprime, que reproduz os dados da sensibilidade, mas que constrói os conhecimentos”.

É pertinente destacar também que os desenhos da Figura 4 mostram variadas posturas, movimentos e certa liberdade no espaço em que se encontram. Pela expressão facial, os personagens comunicavam indícios de alegria, motivação e entusiasmo.

Sob outra perspectiva, considerou-se que para ter acesso à informação e ao conhecimento, não há barreiras ou fronteiras e, portanto, o ensino e a aprendizagem podem ocorrer em diferentes locais, por variados meios, métodos e recursos (Figura 5):

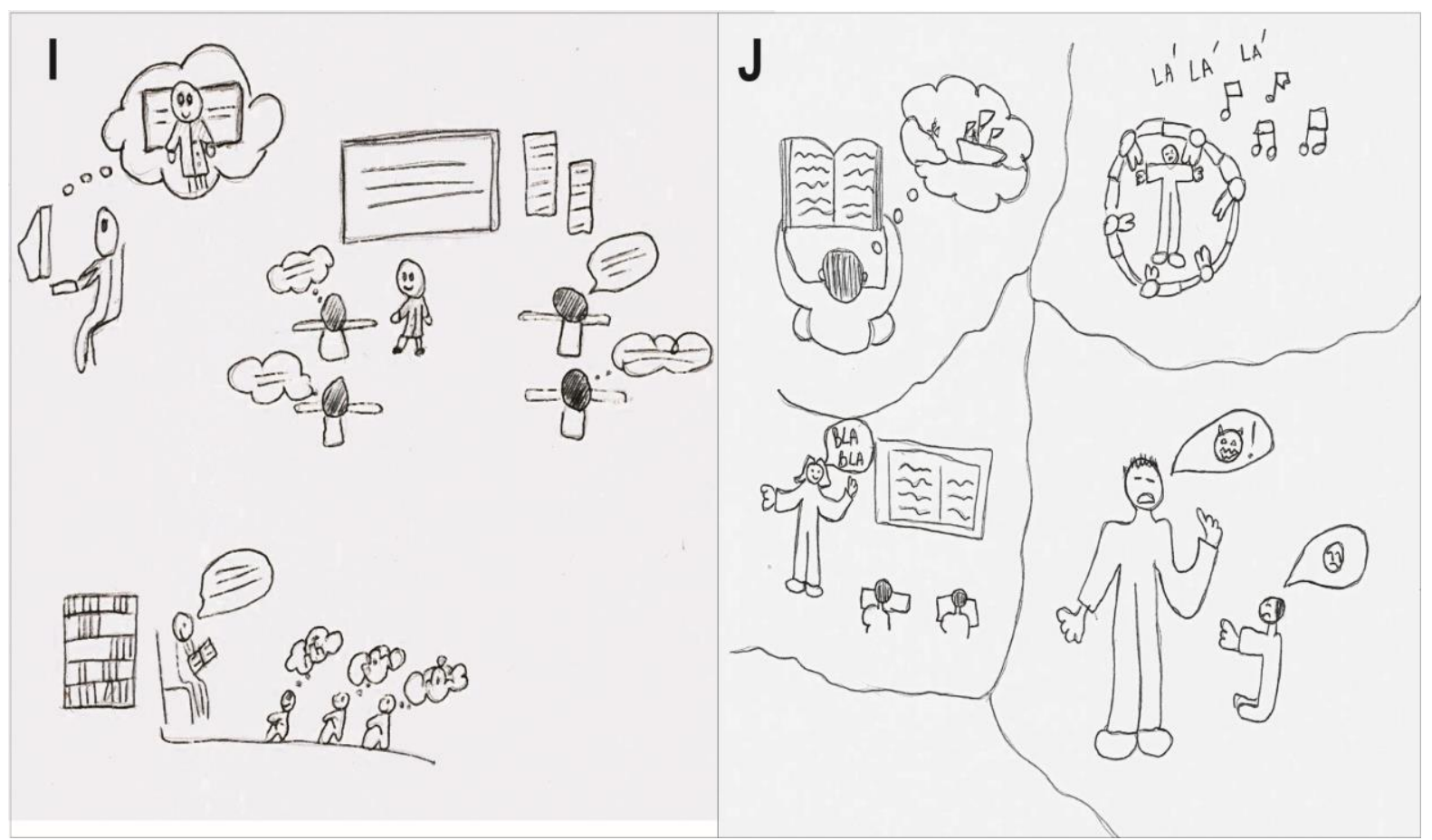

Figura 5 - Desenhos de acadêmicos de licenciatura sobre o conhecimento em diferentes ambientes e de variados métodos e recursos.

Fonte: Os autores. Autor do Desenho I: acadêmico 15 e desenho J: acadêmico 4.

Nos Desenhos I e J foi possível notar a mensagem de que o conhecimento se concretiza com a interação dos sujeitos, com o interesse e atenção voltados para o mesmo assunto e, nesse processo, vão criando conexões. Essa ideia corrobora com Masschelein e Simons (2014), que citam discursos sobre as transformações e variedade dos ambientes e momentos de aprendizagem. Considerando-se não haver um padrão formatado para todos e que são espaços e indivíduos heterogêneos, como pressupor uma forma homogênea de ensinar e aprender?

Como foi demonstrado nas Figuras 1 a 5, cada produção é única e autêntica. É possível reconhecer que toda imagem sugere determinadas concepções sobre conhecimento, escola e docência, conforme vislumbram em seu contexto, experiências e possíveis expectativas. Tal exercício se relaciona ao sentido da educação. 
Amparados em Banks (2009), reconhecemos que a criação de imagens pelos sujeitos pesquisados é relevante e serve para documentar e analisar o tema estudado. $\mathrm{O}$ foco, ao analisar os desenhos foi buscar possíveis retratos, ilustrações ou representações desses participantes com o conhecimento.

Concordamos com Loizos (2012, p. 137) ao afirmar que a imagem "oferece um registro restrito, mas poderoso das ações temporais e dos acontecimentos reais - concretos, materiais". Bauer, Gaskell e Allum (2012) classificam os desenhos como dados sociais de comunicação informal e, assim sendo, valorizam o interesse sobre expressões espontâneas.

Em última análise, foram geradas mais três categorias, a partir da observação de todos os desenhos. A primeira se refere aos sujeitos no contexto de ensino e aprendizagem (professores e estudantes). Para tanto, observando as imagens, averiguamos indícios da presença da figura docente e características desses personagens. Os resultados foram expressos do Quadro 1.

Quadro 1 - Caracterização descritiva dos professores representados em desenhos produzidos pelos licenciandos.

\begin{tabular}{|c|c|c|}
\hline Características & Opções & Quantidade \\
\hline \multirow{2}{*}{ Representação do professor } & Sim & 10 \\
\hline & Não & 5 \\
\hline \multirow{3}{*}{ Gênero } & Feminino & 7 \\
\hline & Masculino & 1 \\
\hline & Não foi identificado & 2 \\
\hline \multirow{6}{*}{ Vestimenta } & Saia & 4 \\
\hline & Jaleco & 2 \\
\hline & Blusa & 4 \\
\hline & Calça & 3 \\
\hline & Sem detalhes de roupas & 2 \\
\hline & Sandálias e sapatos & 3 \\
\hline \multirow{3}{*}{ Expressividade do corpo } & Em pé, falando ou explicando algo & 8 \\
\hline & Em pé, escrevendo no quadro & 1 \\
\hline & Não foi desenhado o corpo & 1 \\
\hline \multirow{2}{*}{$\begin{array}{l}\text { Ordem/distribuição em relação aos } \\
\text { estudantes }\end{array}$} & $\grave{A}$ frente da turma, distante dos alunos & 7 \\
\hline & Próximo dos alunos & 3 \\
\hline
\end{tabular}

Face ao exposto, notou-se a figura do professor e da professora com alguns traços marcantes, sendo, em sua maioria: mulheres, à frente da turma, distantes dos estudantes. Comumente, o profissional registra os conteúdos e/ou informações no quadro e explica, sendo evidenciado como uma figura central no processo que sugere a preponderância da comunicação verbal.

No que se refere aos estudantes, apresenta-se o seguinte resultado (Quadro 2): 
Quadro 2 - Caracterização descritiva dos alunos representados em desenhos produzidos pelos licenciandos.

\begin{tabular}{|c|c|c|}
\hline Características & Opções & Quantidade \\
\hline \multirow[b]{2}{*}{ Representação dos estudantes } & Sim & 15 \\
\hline & Não & 0 \\
\hline \multirow[t]{3}{*}{ Gênero $^{7}$} & Feminino & 7 \\
\hline & Masculino & 10 \\
\hline & Não foi identificado & 84 \\
\hline \multirow{5}{*}{ Vestimenta } & Vestido & 1 \\
\hline & Saia & 2 \\
\hline & Blusa & 7 \\
\hline & Calça & 5 \\
\hline & Sem detalhes de roupas & 86 \\
\hline \multirow{7}{*}{ Expressividade do corpo } & Em pé, falando ou interagindo & 2 \\
\hline & $\begin{array}{l}\text { Em pé, aparentemente alheio ao estudo } \\
\text { proposto }\end{array}$ & 33 \\
\hline & Fazendo atividade prática & 9 \\
\hline & Sentados, passivos & 39 \\
\hline & $\begin{array}{l}\text { Sentados, com representação de } \\
\text { pensamento }\end{array}$ & 13 \\
\hline & Sentados, com representação de fala & 3 \\
\hline & Não foi desenhado o corpo & 2 \\
\hline
\end{tabular}

Fonte: Os autores.

O alunado foi o maior grupo identificado e apareceu em todos os desenhos. Muitos foram retratados sentados e aparentemente passivos, enquanto outros pareciam alheios, dispersos ao conteúdo estudado, com outros interesses. É pertinente observar a postura e movimentação corporal nos desenhos de estudantes: sendo evidenciada, na maioria: alunos sentados, direcionados ao professor e enfileirados. Outros dialogam, interagem, movimentamse e fazem atividades práticas.

A segunda categoria se remete as interações, relacionamento interpessoal e $\operatorname{comportamentos}^{8}$ (Quadro 3):

Quadro 3 - Caracterização descritiva de interações, relações e comportamentos representados em desenhos produzidos pelos licenciandos.

\begin{tabular}{|l|l|c|}
\hline Características & Opções & Quantidade \\
\hline \multirow{2}{*}{$\begin{array}{l}\text { Interações, } \\
\text { relações e }\end{array}$} & Interagindo com o professor/colegas & 14 \\
\cline { 2 - 3 } comportamentos $^{9}$ & Todos voltados para o professor, aparentemente prestando atenção & 8 \\
\cline { 2 - 3 } & A turma fica dividida (alguns claramente atentos, outros dispersos) & 3 \\
\cline { 2 - 3 } & Todos os alunos estão dispersos & 1 \\
\hline
\end{tabular}

Fonte: Os autores.

\footnotetext{
${ }^{7}$ Em alguns desenhos observou-se mais de um estudante, em razão disso o número de alunos ultrapassa 15 (total 101).

${ }^{8}$ Nesta, foram observadas as possíveis interações dos sujeitos neste processo e considerou-se os gestos, o posicionamento e a postura - além das observações já apresentadas na primeira categoria sobre os professores e estudantes.

${ }^{9}$ Considerando que alguns acadêmicos desenharam mais de um ambiente ou cena de interação, a quantidade de cada opção ultrapassou o total de atividades produzidas.
} 
Essa categoria serve para complementar outras observações apresentadas nos Quadros 1 e 2. Notou-se fortemente presente a interação entre os sujeitos, o que supõe uma ideia de relação interpessoal. Também foi percebida certa semelhança quando retrataram todos os estudantes voltados para o professor ou para a professora, numa postura física semelhante, ou todos dispersos, supostamente alheios ao processo de ensino e de aprendizagem, indisciplinados ou desinteressados.

Por fim, a terceira categoria refere-se às representações dos locais e recursos de ensino e de aprendizagem ${ }^{10}$ (Quadro 4):

Quadro 4 - Caracterização descritiva dos espaços e recursos.

\begin{tabular}{|c|c|c|}
\hline Características & Opções & Quantidade \\
\hline \multirow{7}{*}{ Ambientes e espaços } & Sala de aula & 11 \\
\hline & Espaço de leitura/biblioteca & 2 \\
\hline & Espaço de música, brincadeira de roda & 1 \\
\hline & Horta & 1 \\
\hline & Ambiente virtual & 1 \\
\hline & Refeitório & 1 \\
\hline & Quadra esportiva & 1 \\
\hline \multirow{3}{*}{$\begin{array}{l}\text { Sala de aula (disposição de } \\
\text { carteiras) }\end{array}$} & Carteiras enfileiradas & 9 \\
\hline & Foi representado apenas um aluno & 1 \\
\hline & Não foi representada sala de aula & 3 \\
\hline \multirow{10}{*}{ Recursos } & Quadro & 11 \\
\hline & Carteiras & 5 \\
\hline & Caderno/livro & 5 \\
\hline & Giz & 9 \\
\hline & Instrumentos de laboratório & 1 \\
\hline & Data show & 2 \\
\hline & Ferramentas de jardinagem & 1 \\
\hline & Computador & 1 \\
\hline & Caneta/lápis & 1 \\
\hline & Régua (para indicar a escrita do quadro) & 3 \\
\hline
\end{tabular}
Fonte: Os autores.

Os ambientes e espaços identificados mostraram diferentes possibilidades de contextos para situações de ensino e aprendizagem. Entre esses, a sala de aula foi mais lembrada, prevalecendo o padrão de carteiras e cadeiras enfileiradas, quadro e giz. Outros ambientes foram retratados, como a biblioteca, quadra esportiva, lugares abertos, ambientes virtuais, refeitório e a horta.

\section{CONSIDERAÇÕES FINAIS}

Em abordagem política, sociológica e filosófica, é possível considerar que o acesso ao conhecimento científico é desigual, assim como é a sociedade. Nesse contexto, ao pensar

\footnotetext{
${ }^{10}$ São descritas as figuras do ambiente, dos locais e recursos presentes e trata-se de um olhar voltado para os objetos e as características dos espaços representados nos desenhos.
} 
na função da escola, é necessária a defesa pelo conhecimento científico, sistematizado. De igual modo, é indispensável que o professor e a professora compreendam e identifiquem sua postura epistemológica para, assim, refletir acerca de seu fazer docente.

Oliveira (2016), Becker (2012) e Gimeno Sacristán (2000) defendem que a epistemologia faça parte da formação de professores. No entanto, é possível considerar um tema que necessita ser mais discutido e estudado nos cursos de licenciatura.

As produções sugerem determinados entendimentos e reflexões dos acadêmicos e, ao mesmo tempo, propiciam outras ideias e significados que podem cooperar no exercício de pensar, refletir e expressar as concepções de conhecimento, num sentido epistemológico que, embora pouco presente na formação, intervém na prática e na ação docente.

De forma geral, as atividades elaboradas pelos participantes expressaram diferentes olhares acerca do conhecimento e da escola, retratando possíveis experiências vivenciadas na trajetória discente ou perspectivas sobre a docência.

A síntese das respostas mostrou preceitos de conhecimento envolvendo resultado, reprodução, aprendizagem, ser aplicado e validado, mutável, historicamente acumulado, transmitido. Nos desenhos, prevaleceram retratos de transmissão de conhecimento em uma vertente diretiva em que o professor expõe o conteúdo, enquanto o aluno passivamente recebe e escuta. Vimos ainda alusão a conteúdos impostos e prescritos aos professores e estudantes.

Esses aspectos se assemelham a estudos sobre a epistemologia empirista, que caracterizam-se por: valorizar a memória, a captação de informações, a aula expositiva, a hierarquia; enfatizar o ensino como transmissão de conhecimentos; considerar a aprendizagem como soma e acumulação (ARANHA, 1996; BECKER 2012, 2013). Essa epistemologia pode ser identificada em metodologia tradicional de ensino, na organização do espaço, nas formas de relação entre os indivíduos, na seleção de conteúdo, no entendimento de que o conhecimento pode ser transmitido e a aprendizagem provada. Desse modo, parece haver uma "caricatura" sobre como deve[ria] ser o ensino.

Por outro lado, foram identificadas formas que apresentam características do construtivismo, com ênfase à interação e à ação. Essa concepção favorece outras metodologias e organizações no espaço escolar e pode ser colocada como uma alternativa à prática política pedagógica, conforme se pôde constatar em algumas atividades.

Reconhecemos a necessidade de superar a compreensão de que a escola se restrinja a transmissão e reprodução de conhecimentos. Para tal mudança epistemológica, a prática pedagógica deve ser consoante àquela que percebe que o conhecimento também pode ser construído (BECKER, 2012) e produzido (CHASSOT, 2016) no âmbito escolar.

É importante ter presente que o conhecimento científico deve ser valorizado e assumido pela escola, pelo professor, pela professora, pelo estudante. É preciso olhar, analisar 
e reconhecer dimensões epistemológicas, pois essas são expressas e representadas em aspectos metodológicos, nas relações interpessoais e outros quesitos do planejamento e da prática docente. Por tais questões, é fundamental que a epistemologia faça parte da formação inicial de professores.

\section{REFERÊNCIAS}

ARANHA, M. L. A. Filosofia da Educação. 2 ed. rev. e ampl. São Paulo: Moderna, 1996.

BANKS, M. Dados visuais para pesquisa qualitativa. Tradução: José Fonseca. Consultoria, supervisão e revisão técnica: Caleb Farias Alves. Porto Alegre: Artmed, 2009.

BARDIN, L. Análise de Conteúdo. Tradução: Luís Antero Reto, Augusto Pinheiro. São Paulo: Edições 70, 2011.

BAUER, M. W.; GASKELL, G.; ALLUM, N. C. Qualidade, quantidade e interesses do conhecimento: evitando confusos. In: BAUER, M. W.; GASKELL, G. (orgs.). Pesquisa qualitativa com texto, imagem e som: um manual prático. Tradução: Pedrinho A. Guareschi. 10 ed. Petrópolis: Vozes, 2012. p. 17 - 36.

BECKER, F. Educação e construção do conhecimento. 2 ed. Porto Alegre: Penso, 2012. Vozes, 2013. A epistemologia do professor: o cotidiano da escola. 16 ed. Petrópolis:

CHASSOT, A. Alfabetização científica: questões e desafios para a educação. 7 ed. Ijuí: Unijuí, 2016.

CHIZZOTTI, A. Pesquisa qualitativa em ciências humanas e sociais. Petrópolis: Vozes, 2006.

COUTINHO, C.; LISBÔA, E. Sociedade da informação, do conhecimento e da aprendizagem: desafios para Educação no século XXI. Revista de Educação, v. XVIII, n. 1, p. 5-22, 2011. Disponível em:

<http://revista.educ.ie.ulisboa.pt/arquivo/vol_XVIII_1/artigo1.pdf>. Acesso em: 10 set. 2017.

CUNHA, M. I. A relação professor-aluno. In: VEIGA, I. P. A. (org.). Repensando a didática. 29 ed. Campinas: Papirus, 2012.

FREIRE, P. Pedagogia do Oprimido. 17 ed. Rio de Janeiro: Editora Paz e Terra, 1987.

FRIGOTTO, G. Projeto societário, ensino médio integrado e educação profissional: o paradoxo da falta e sobra de jovens qualificados. In: PARANÁ. Secretaria de Estado da Educação. Superintendência da Educação. Departamento de Educação e Trabalho. O ensino médio integrado à educação profissional: concepções e construções a partir da implantação na Rede Pública Estadual do Paraná. Curitiba: SEED, 2008.

GIMENO SACRISTÁN, J. O currículo: uma reflexão sobre a prática. Tradução: Ernani F. da F. Rosa. 3 ed. Porto Alegre: Artmed, 2000.

. O currículo na sociedade da informação e do conhecimento. In: GIMENO

SACRISTÁN, J. (org.) Saberes e incertezas sobre o currículo. Tradução: Alexandre Salvaterra; revisão técnica: Miguel Arroyo. Porto Alegre: Penso, 2013.

LIBÂNEO, J. C. Didática. 2 ed. São Paulo: Cortez, 2013.

. Políticas educacionais no Brasil: desfiguramento da escola e do conhecimento escolar. Cadernos de Pesquisa, v. 46, n. 159, p.38-62, jan./mar.2016. Disponível em:

$<$ https://www.scielo.br/pdf/cp/v46n159/1980-5314-cp-46-159-00038.pdf $>$. Acesso em: 2 jun. 2020. 
LOIZOS, P. Vídeo, filme e fotografias como documentos de pesquisa. In: BAUER, Martin W.; GASKELL, G. (orgs.). Pesquisa qualitativa com texto, imagem e som: um manual prático. Tradução: Pedrinho A. Guareschi. 10 ed. Petrópolis: Vozes, 2012. p. 137 - 155.

LUCKESI, C. C. Avaliação da aprendizagem componente do ato pedagógico. São Paulo: Cortez, 2011.

MASSCHELEIN, J.; SIMONS, M. Em defesa da escola: uma questão pública. Tradução: Cristina Antunes. 2 ed. Belo Horizonte: Autêntica, 2014.

OLIVEIRA, I. A. Epistemologia e educação: bases conceituais e racionalidades científicas e históricas. Petrópolis: Vozes, 2016.

PEIXOTO, M. I. H. Arte e grande público: a distância a ser extinta. Campinas: Autores Associados, 2003.

SAVIANI, D. Pedagogia histórico-crítica: primeiras aproximações. 11 ed. rev. Campinas: Autores Associados, 2011.

Associados, 2013.

História das ideias pedagógicas no Brasil. 4 ed. Campinas: Autores

\section{SOBRE OS AUTORES}

AUTOR 1. Pedagoga do Instituto Federal do Paraná (IFPR), campus Paranavaí. Possui mestrado em Ensino pela Universidade Estadual do Paraná (UNESPAR) e é doutoranda em Educação para a Ciência e a Matemática pela Universidade Estadual de Maringá (UEM). Participou da pesquisa-ação, planejando e conduzindo os encontros. Fez a revisão de literatura, análise de conteúdo e escrita.

AUTOR 2. É licenciada em Ciências Biológicas e Mestra em Ensino pela Universidade Estadual do Paraná (UNESPAR). Atua como professora na Secretaria de Estado da Educação do Paraná (Seed-PR). Participou da pesquisa na revisão de conteúdo, textual e de normas. Encaminhou o trabalho para revisão ortográfica, com profissional da área de Letras.

AUTOR 3. É licenciado em Ciências Ensino Fundamental com habilitação em Matemática, bacharel em Engenharia de Alimentos e Mestre em Ensino pela Universidade Estadual do Paraná (UNESPAR). Professor de Matemática na Secretaria de Estado da Educação do Paraná (Seed-PR). Participou da pesquisa na escrita, revisão de conteúdo, textual e de normas. Fez a tradução do título, palavras-chave e resumo para a língua inglesa.

AUTOR 4. Possui graduação em Ciências de Primeiro Grau e em Química, mestrado e doutorado em Engenharia Química pela Universidade Estadual de Maringá (UEM). Professora aposentada da Universidade Estadual do Paraná (UNESPAR). Atua como docente permanente no Programa de Pós-Graduação stricto sensu Mestrado em Ensino: Formação Docente Interdisciplinar, da UNESPAR, campus Paranavaí. Orientou e supervisionou a pesquisa-ação, participando dos encontros com os estudantes. Orientou e participou da pesquisa e da escrita do trabalho, assim como na revisão de conteúdo, do texto e normas. 